\title{
A framework for business renovation: Toward an intellectual infrastructure for the extended enterprise
}

\author{
Yusaku Shibata \\ Nagoya University of Foreign Studies \\ 57 Takeyama, Iwasaki-Cho, Nissin-City, Aichi 470-01 Japan \\ PH:+81-5617-4-1111, FX:+81-5617-5-1729 \\ E-Mail:PXX11310@niftyserve.or.jp
}

\begin{abstract}
The major challenge for manufacturing enterprises in the next century is not the competition between the richest areas of the world, but the contribution they have to make to the development of the sustainability of the planet and of an economy which will serve the needs of around ten billions people. Because responsibilities to respond to the challenge extend well beyond the capability of the individual manufacturing enterprise, cooperation between enterprises, professional societies, research and educational institutions and governments is essential.

Although the specification of requirements is one of most important premises in solving such a complex problem, the requirements for business renovation are very vague and not well defined now. This is not for lack of general recognition of its importance in the industry and the academic circles. It may be for extreme difficulty in establishing and sustaining a good cooperation between researchers and practitioners. Such an understanding suggests us to simultaneously pursue a study of a new framework for cooperation and a research of requirements engineering itself. This paper proposes a new concept of research based upon above mentioned observation and reports a case study of requirements modelling, making full use of a new intellectual infrastructure named "SINPL-MEGANET".
\end{abstract}

\section{Keywords}

Catalyst, design theory, enterprise integration, extended enterprise, holonic system, integrating platform, requirements engineering, self-organization, sustainable development 


\section{THE CHALLENGE FOR MANUFACTURING ENTERPRISES}

Manufacturing enterprises are experiencing profound changes, which are caused by a historical transformation which is rearranging the politics and economics of the next century. They are gradually, often painfully, shifting from traditional high volume production to high value creation, where profits derive not from scale and volume but from continuous discovery of new linkages between needs and solutions. The high value enterprise is driven forward by three different but related types of professionals - problem identifiers, problem solvers, and strategic coordinators, who should be in direct contact with one another to continuously discover new opportunities and are called "symbolic analysts". A remaining dilemma is "how do we ensure that symbolic analysts apply their creative energies in the right direction?" Perhaps, "the proper response is to organize the market in ways that motivate symbolic analysts to discover means of helping mankind while inflicting the least amount of harm". (Reich 1992, p.186)

In this respect, Heilbroner (1993, pp.116-118) sketches a framework of possible response to this dilemma. The mitigating principle for the next century "would be 'participation' - the engagement of all citizens in the mutual determination of every phase of their economic lives through discussion and voting". Although the transition to that direction "is too difficult, the rearrangements too complex, and above all, the opposition too ferocious for any such truly revolutionary change to occur in so short a time.....the ideas and the ideals of a participatory society would serve us to good purpose while we wrestle with the huge problems of making capitalism work as well as possible and as long as possible. During the se years, when tensions and failures are more likely to be the order of the day than resolutions and successes, it will help to have alternative future destination in our imaginations" as shown in Figure 1.(bold letters by the author)

\section{THE ROLE OF FRAMEWORK IN SOLVING COMPLEX PROBLEMS}

The idea behind developing frameworks for business renovation is that an essential part of renovation projects - as required for the extended enterprise - is in fact similar and common in every type of business. Thus it could be captured, standardized and utilized instead of developing it again from scratch. Once standardized, generally accepted frameworks can be supported by tools, methodologies, and a range of compatible products thus making the entire endeavor feasible, which otherwise is practically impossible in time and cost. (Williams et al. 1993)

A good example is the principles Jack Welch is using to revolutionize GE:

"The rules for succeeding in business in the nineties have changed radically from eighties. Control Your Destiny or Someone Else Will superbly defines those changes and explains how Jack Welch engineered one of the most successful transformation of a corporate culture in American business history. Anyone at any level in business will 
profit from this account of the renaissance of GE." (Rosen of Compaq in Tichy and Sherman 1994)

Therefore, some of the principles of Welch as described in "Control Your Destiny or Someone Else Will" are used as the starting points of proposing a framework in the following sections and written in bold letters. Also hereafter, words "principle", "framework", "architecture" and "model" are used in a same meaning and therefore interchangeably.

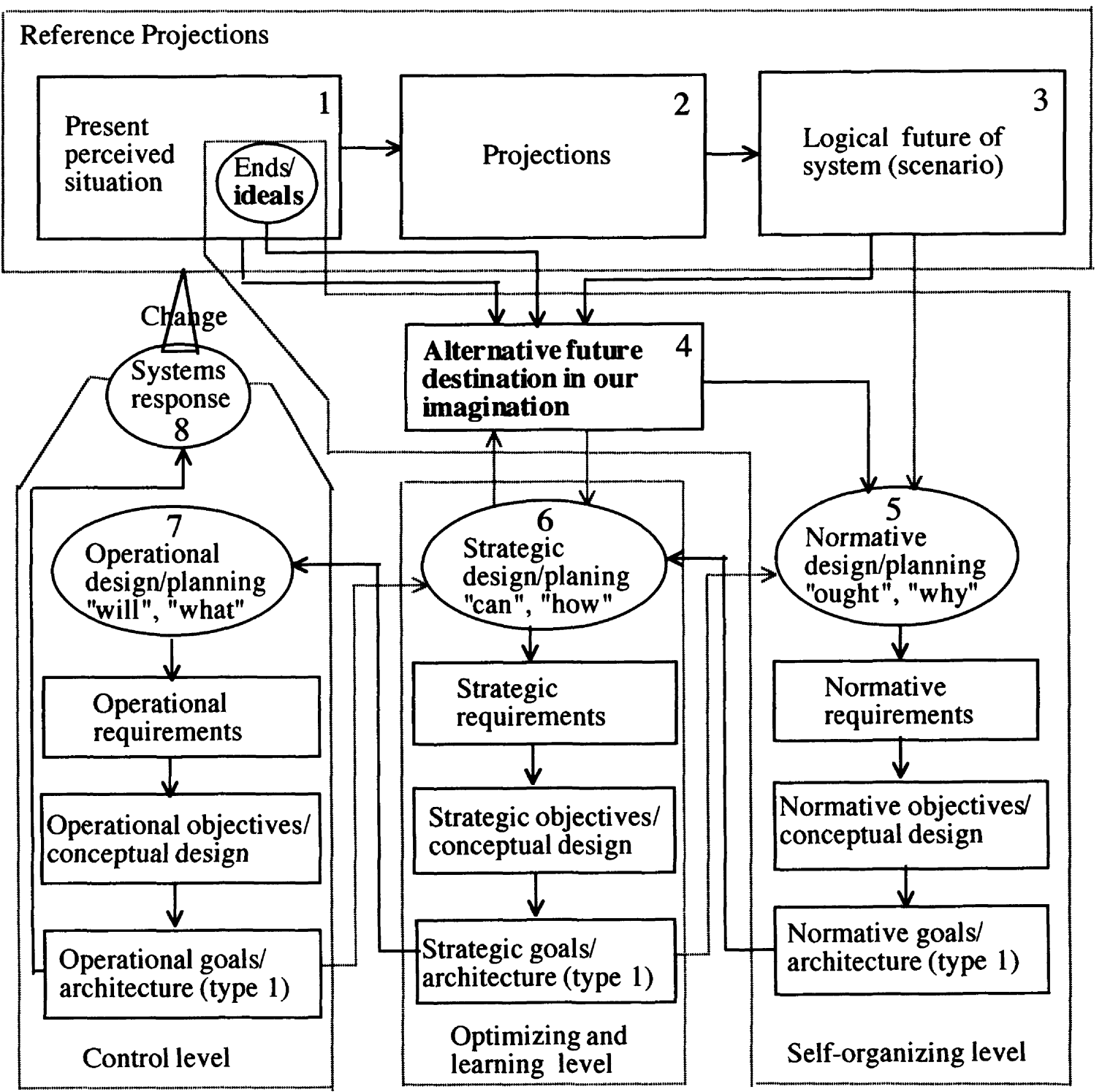

Figure 1 This diagram shows seven steps in design and impmementation process of an integrated system, which presents Type 1 Architectures and the development processes, and therefore can be called Type 2 Architecture. (Ozbekhan 1974, modified) 


\subsection{A definition of architecture in enterprise integration process}

"ARCHITECTURE: The practice of designing and building structures (Webster's Collegiate Dictionary)" (Tichy and Sherman 1994, p.420)

There are a multitude of proposed architectures and models which purport to guide the task of integrating enterprises. However, only a few of these actually treat the "how" of enterprise integration as well as the "what" that is needed and the remainder concentrate on describing the structure of the computer system involved, i.e., the "what" only as described below. Thus, all architectures can be classified into two types:

1. Those which describe the architecture of the integrated system, such as the computer system, the communication system, etc. These will be called Type 1 Architecture.

2. As shown in Figure 1, those which illustrate the life life cycle of the project developing the integrated enterprise. These will be labeled as Type 2 Architecture, just Architecture or Framework in this paper. (Williams et al. 1993)

\subsection{R\&D framework for the full scale IMS program}

The framework of R\&D themes, as shown in Figure 2 and described below, was proposed by the International Technical Committee (ITC) of the Intelligent Manufacturing Systems program (IMS) to "encourage possible project applicants to develop proposals which show a clear contribution to the necessity of global cooperation." (IMS Promotion Center 1994)

Total product life cycle issues

$<$ Future models of manufacturing systems $>$ The proposals of "agile manufacturing", "fractal factory", "bionic manufacturing", "holistic enterprise integration", etc.

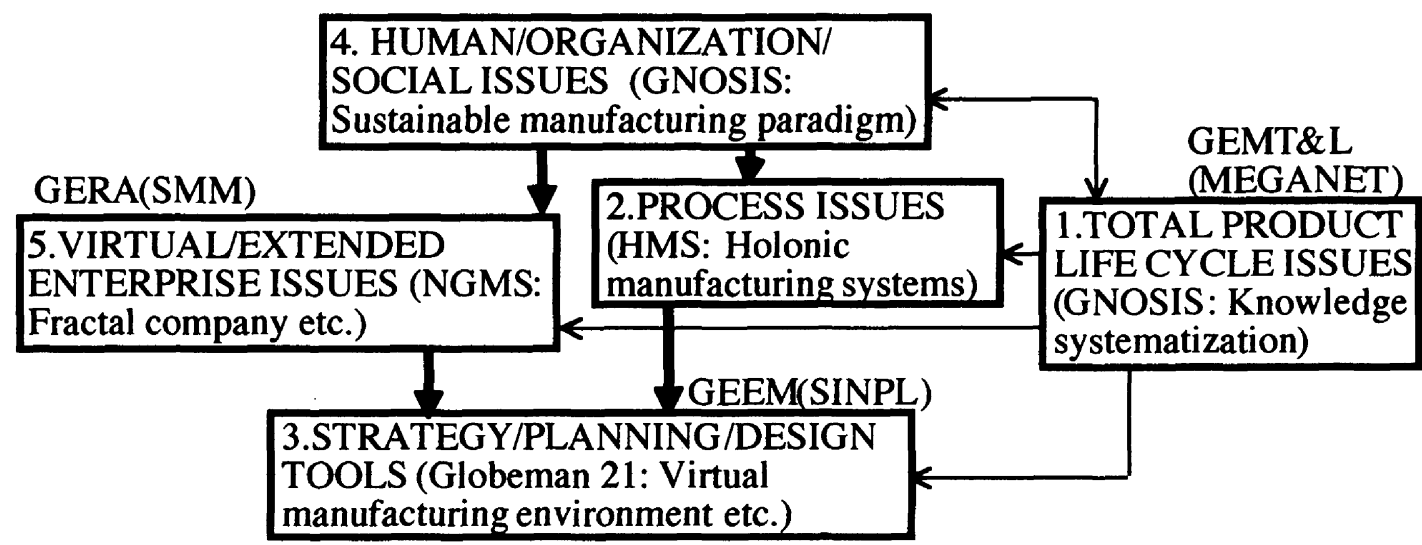

Notes:

1. Descriptions in capital letters and in frames are research themes for IMS program.

2. Others in frames are typical proposals by international consortia for IMS program.

3. Descriptions beside frames are proposals by IFAC/IFIP Task Force and the author.

Figure 2 Relationships between research areas for IMS program (arranged by the author) 
<ntelligent communication network $>$ To understand the productivity of global distribution and sourcing the communication networks and their applications have to be improved.

Environment protection, minimum use of resources $>$ The complexity of these issues can only be handled via cooperation with a variety of specialists. Because the conditions in that field are very different in different regions, a common understanding and harmonized views for the response of manufacturing technologies are necessary.

$<$ Recyclability $>$ Up to now it is nearly impossible to recycle a product of one region in another region. In the longer term that situation may damage the free trade between regions. Therefore new ideas for global recyclability should be developed under the IMS umbrella. $<$ Economic justification methods $>$ In spite of the manufacturing scientists the speed of new problems arrival has by far outranged the output of their solutions. Very often this is caused by non harmonized assessment and economic justifications of new manufacturing systems. Therefore IMS should support projects with development of clear specifications for economic justification methods.

\section{Process issues}

To realize the needs for rapid response to changing requirements, the following themes can be identified: Methods that can quickly produce different products through "Rapid Prototyping"; manufacturing processes that can minimize effects on environment and resources; recyclability and refurbishment; improvement in the flexibility and autonomy of processing modules; improvement in interaction among various components of manufacturing; intelligent communication network systems to understand changing requirements.

\section{Strategy/planning/design tools}

Keywords of new production paradigms are creativity and flexibility. The move towards hetrarchical structures will continue to require major changes in organizations, systems and work practices. We need methodologies and tools to help us to define appropriate manufacturing strategies and to design appropriate organizations and business processes:

Methods and tools to support business process re-engineering

Modelling tools to support the analyses and development of manufacturing strategies

Design support tools to support planning in an virtual/extended enterprise environment

\section{Human/organization/social issues}

Engineering education in schools and enterprises should be restructured to meet the needs of society. This necessitates a change in priorities and closer ties between industry and educational institutions. In addition, the necessity of re-orientation should be applied to the concept of offshore plant as a whole. Giving more autonomy to these plants enables them to react more flexibly to changing conditions in the areas where they are based, and is consistent with organizational ideas of decentralization, empowerment and hie rarchy flattening. It al so serves to contribute to domestic development in the countries where the plants are located and further the IMS goal of spreading widely basic manufacturing knowledge. ITC considers as projects globally recognized, strong professional societies and educational institutions for the promotion of manufacturing as a discipline. 


\section{Virtuallextended enterprise issues}

The extended enterprise is an expression of the market driven requirement to embrace external resources in the enterprise without owning them. The operation of the extended enterprise requires take up of communications and database technologies which are near to the current state of the art. However, the main challenge is organizational rather than technological. Research and development opportunities in this area are:

Methodologies to determine and support information processes and logistics across the value chain in the extended enterprise

Architecture to support concurrent engineering across the extended enterprise

Methods to assign cost/liability/risk and reward to elements of the extended enterprise

Team working across individual units within the extended enterprise, etc.

\subsection{Three components of framework for business renovation}

The IFAC/IFIP Task Force on Architectures for Enterprise Integration (hereafter just IFAC/IFIP Task Force) early recognized that a single, universally accepted architecture would be a major contribution to the field of enterprise integration. However, failing to find an acceptable candidate from among those currently available as well as to synthesize a new architecture from the best characteristics of existing architectures, seemingly for political rather than technical reasons, IFAC/IFIP Task Force has decided that this new architecture should be developed only as far as the specification stage. Thus, they are now completing a specification and statement of requirements (Garlan 1994) for a Generic Enterprise Reference Architecture and Methodology called GERAM, which is made of three major components:

Generic Enterprise Reference Architecture: GERA

Generic Enterprise Engineering Methodology: GEEM

Generic Enterprise Modelling Tools and Languages: GEMT\&L

In addition, they believe that the same GERAM can be used to describe not only the manufacturing enterprise itself, but also three other related enterprise activities as well:

Strategic enterprise management process life cycle

Enterprise engineering/integration process life cycle

Enterprise life cycle

Product life cycle

"Such a concept of universal usage of the principles of enterprise refe rence architecture applicability in all areas of human endeavor today has major ramification on the importance and potential future use of the result of the IFAC/IFIP Task Force's work. (Williams 1994)" For the moment, such a development remains open ended. Nevertheless, its overall configuration, its main concepts and phases, are now sufficiently general so that one can describe and discuss them without specific cases. The purpose of this paper is precisely to do that and to extend and apply the concept to the "extended enterprise development process life 
cycle". In accordance with the thinking of IFAC/IFIP Task Force, the new framework for business renovation will also be composed of following three major components:

Structural model

Process model

Tools and languages

Main sources for the following discussions are:

Framework for problem identifiers

IMS-----(IMS Promotion Center 1995, British Aerospace PLC 1994)

Framework for problem solvers

IFAC/IFIP Task Force---(Williams et al. 1993, Bernus and Nemes 1994)

CIMOSA------------(Vernadat 1994)

Framework for strategic coordinators

Shibata-------o---(Shibata 1984, 1993)

\section{STRUCTURAL MODEL}

\subsection{Framework for structural problem identifiers}

"Social architecture is the art of designing and building a complex organization. Welch characterizes his vision for the next century with the word 'boundarylessness'. 'Old Way' organizations were all about boundaries and compartmentalization and chainsof-command. The new organization would be free of these increasingly nonproductive strictures. Information would flow freely across functional and business boundaries from where it was developed to where it was needed." (Tichy and Sherman 1994, p.420)

The Consortium for Advanced Manufacturing International (CAM-I) is coordinating the IMS/NGMS (Next Generation Manufacturing Systems) program, which is starting to develop a vision of NGMS and technical agenda describing a set of technical and systems R\&D projects as the first step of international cooperation. Their objectives are to develop and integrate the best ideas for the next generation manufacturing enterprises which will consist of globally distributed autonomous work units and be called virtual enterprises. A clear challenge for virtual enterprises is that all work units share a view of what the market place is demanding and share a responsible corporate strategy.

The next question is how do we create manufacturing organizations that have these characteristics? Many unique and mutually complementary concepts and models are proposed from international partners of NGMS consortium: Fractal company from Europe (Kuehnle et al. 1995); autonomous distributed systems and bionic manufacturing systems from Japan; agile manufacturing from the U.S.A.; important view of smaller enterprises from Australia. Because these concetpts have a strong commonality, they will be easily integrated into a single harmonized NGMS. 


\subsection{Framework for structural problem solvers}

The enhanced use of modelling and simulation to verify product and process designs has been called the "virtual manufacturing". It allows easy reconfiguration and extension of a system by offering systematic and modularized knowledge of manufacturing. The concept of virtual manufacturing will enable a comprehensive model representation framework, by which all the necessary models can be integrated, and activities of enterprise engineering will be well represented and executed.

IFAC/IFIP Task Force is developing Generic Enterprise Reference Architecture (GERA) as one component of Generic Enterprise Reference Architecture and Methodology (GERAM). GERA is the definition of enterprise related concept, with the primary focus on the life cycle of enterprise. Since the life cycle can be considered as a design process the architecture will also have to identify the results of this design process.

Principles of CIMOSA Modelling Framework will be considered usefully in developing GERA. The CIMOSA Modelling Framework (also known as the CIMOSA Cube) is based on three orthogonal principles:

Derivation principle, which advocates to model enterprises according to three levels

Genericity and reusability principle based on three generic layers

Generation principle, which recommends to model manufacturing enterprises according to four basic but complementary viewpoints (other views could be defined)

\subsection{Framework for strategic coordinators}

Pilot case studies of CIMOSA have shown that the most striking potentials today lay in the field of organization. Starting from the traditional Tayloristic understanding of the enterprise many iterative steps were necessary to arrive at the changement of thinking, which needed a period of learning by doing and some doubts and crises under way for all of the team. The only recently defined constructs for the organization view proved to add an important amendment to the architecture that so far has been very much information technology oriented. At present, specific tools to apply enterprise models unfortunately do not exist. They will simplify modelling and augment user acceptance. (Katzy et al. 1993)

Above mentioned issues require more simplified modelling tools, especially laying emphasis on organizational redesign. An ability to make high quality decisions early in the renovation process is critical to succeed. In other words, the conceptual design phase is crucial. This applies not only to the design of architectures, but also to the planning of human activities at large. Managers and professionals, who are engaged in business process reengineering, must overcome many obstacles, both technical and nontechnical, as shown in Figure 3. Their actions will possibly become more effective if relevant information's and guidelines are timely offered to them based upon some reliable design theory. However, we are unsure about a reliable design theory because, al though the re has been increasing criticism of the ruling design theory - the rational design theory or action model, no set of concepts has emerged that convinces a majority of practitioners that the new paradigm of design theory has been found. 
The recognition that our past paradigm of design might be wrong, or at any rate insufficient, came mostly through advances in systems thinking (Yoshikawa 1992). Thus, the emerging concept of design should have a definitely changed focus, amounting perhaps to a fundamental shift in our world view, toward a systemic vision of reality. It is probably this shift which has caused us to rethink design processes and design models. (Ozbekhan 1974, Hemmens 1980)

In the following chapters, this emerging design paradigm is leading

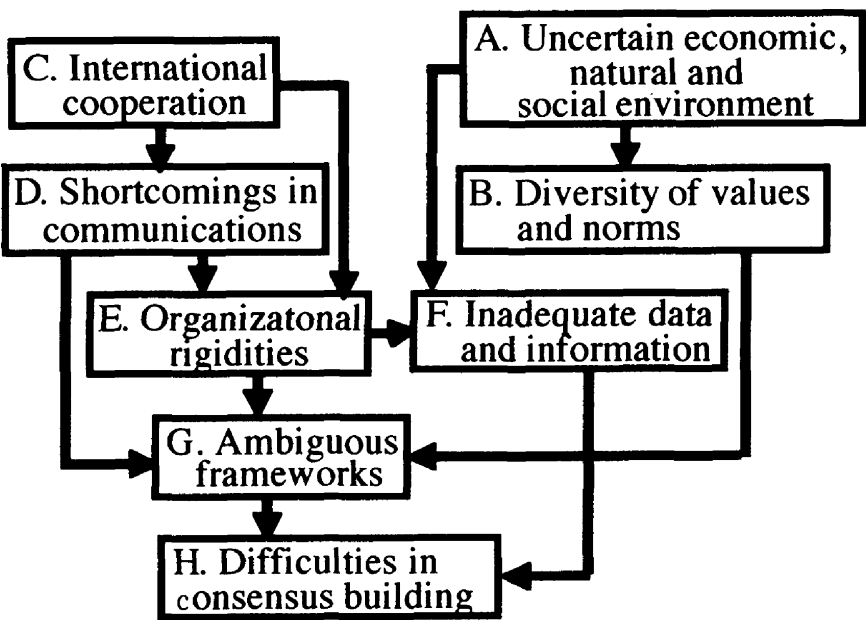

Figure 3 Relational structrue of obstacles in advanced manufacturing (Shibata 1993) to the redefinitions of design process model, in which Figure 3 will be utilized as a framework, or as a Structural Meta-Model (SMM). SMM includes the enterprise model implicitly as a subsystem, which might be a Holonic Manufacturing System (HMS), and suggests relations between the enterprise and its environment. (Koestler 1989, Kurosu 1992)

\section{PROCESS MODEL}

\subsection{Framework for procedural problem identifiers}

"Corporate revolutions follow a predictable set of dynamics. The pain, the resistance, the breakthroughs and joys of successful passages from one phase to another can be understood and mastered by leaders. It is a particular type of drama, which is composed of three acts:

Act 1: A wakening

Act 2: Envisioning

Act 3: Rearchitecting " (Tichy and Sherman 1994, p.368)

The important finding of the IMS/Globeman 21 is that the conventional view of enterprise engineering is probably the wrong way of achieving the expected objectives. Instead, we have to look at something which we call processes. These are the processes that cross all of the organizational boundaries, the processes that really represent the value which the organization adds to the product or service. Global concurrent engineering and global project management are two typical examples of important processes.

We all know that concurrent engineering is important. The difference here is that we are discussing concurrent engineering on a global scale, where borders disappear and time delays 
disappear. Take as an example an aerospace company, building complex one off artifacts. They require hundreds of engineers with differing skills to be able to design that artifact. How we do that is one of the questions we have to answer in a framework like IMS.

A feasibility study of Global Concurrent Engineering (GCE) was carried out within the IMS Test Case 3 under ESPRIT 7752. One of the objectives of the project was to develop an architecture or description model on how to design a product within GCE environment. The framework of study was based on the CIMOSA model and modern systems theory. The IMS/GCE consortium has found provisionally that some modification or extension is necessary for CIMOSA Cube to be applied to GCE. Firstly, CIMOSA architecture should be extended to include cultural view in order to adequately describe the GCE application. Secondly, al though the function view includes a modelling of tasks and dynamic behavior as one component in CIMOSA model, the proposed architecture for GCE deals with these two views separately to emphasize the importance of each view. (Ahmed et al. 1994)

\subsection{Framework for procedural problem solvers}

Generic Enterprise Engineering Methodology (GEEM) is the description of the processes of enterprise integration, in other words a detailed process model, with instructions for each step. The first goal of developing GEEM is to provide one complete methodology which covers the entire GERA architecture. The second goal of developing GEEM is to specialize the methodology such that a consistent set of modelling languages is proposed along with the presentation of procedures.

CIMOSA does not provide a detailed methodology but recognizes several methodologies (to be defined by CIM users using CIMOSA principles according to their needs). However, CIMOSA defines a generic CIM system life cycle, called CIMOSA System Life Cycle, comprising the following major steps and proposed for GEEM:

1. Master plan definition

2. Requirements definition

3. System design

4. System build and release

5. System operation

6. System maintenance and change

7. System dismantlement

\subsection{Framework for strategic coordinators}

As described in section 3.3, the discussion of design theory appears to be stuck and in need of renewal. It is stuck in that the criticisms of the rational design model and proposals of alternatives to it continue to repeat the same arguments and draw familiar ideas. Meanwhile, indifference and hostility of practitioners to researchers of design theory grow. This suggests that we need to simultaneously pursue a search of new framework for cooperation between practitioners and reseachers and a research of design model building itself.

SImplified Normative Planning (SINPL) as shown in Figure 4 seems to be one of 


\begin{tabular}{|l|l|l|}
\hline Soft methodology (Checkland 1981) & SINPL (Shibata 1992) & Welch (Tichy 1994) \\
\hline 1. Expressed problems & Future Scenario & Prologue \\
\hline 2. Root definition & Insight of contradictions & Awakening \\
\hline 3. Conceptual model & Normative objectives & Envisioning \\
\hline 4. Possible solutions & Strategic Plan & Rearchitecting \\
\hline 5. Action plan & Launching tactics & Epilogue \\
\hline
\end{tabular}

Figure 4 Five steps models of design process by various authors

methodologies ideally suited for catalyzing a self-organized modelling process (Shibata 1992). The goal of SINPL is primarily to define the framework of design or to meta-design. The difficulty of meta-design will be alleviated to some extent by using a conceptual framework (meta-rule) of SINPL which consists of design process (meta-process model), problem structure (meta-problem model) and players team organization (meta-role model). A special feature of SINPL is that it does not start from a given problem but from a desirable future vision or a norm, from which the name SINPL is derived. Also S-I-N-P-L explains five workshop steps as described below:

1. Forecasting desirable future (process) and vision $\underline{\text { Scenario (structure) }}$

2. Insight of contradictions (process) and problem structure (structure)

3. New idea proposal (process) and Normative objectives (structure)

4. Strategic Planning (process) and strategic patterns (structure)

5. Action proposal (process) and Launching tactics (structure)

The chief advantage in using SINPL for complex problem solving is that they provide a mode of experimentation with alternative strategies and tactics in a constantly changing environment. The fluid nature of a meta-design approximates the uncertainties encountered in a real situation. The artificially controlled contexts which the conceptual framework of a meta-design imposes build into it certain relationship between the decisions made by some of the players and the response of other stakeholders. But these relationships are unknown initially to the players and are only revealed as the meta-design proceeds. So the outcome of a particular decision or strategy has immediate effects, the reby providing data for analyzing and evaluating the selected course of action with neither the time lag nor the potentially irreversible consequences of a decision in the real world.

\section{TOOLS AND LANGUAGES}

\subsection{Framework for identifiers of requirements for tools and languages}

"To consolidate his power, Welch immediately seized the revolutionary's three main levers of control: the police, the media, and the schools....At GE, the 'schools' were Crotonville. The 'media' included executives' speeches and publications from employee 
magazines to the corporate annual report....GE's 'police' were the cadres of professional nit-pickers and second-guessers on the strategic planning and finance staffs, who reviewed every operation decision and supervised the allocation of capital." (Tichy and Sherman 1994, p.94)

In order to respond to new challenges from the market and society at large, rival companies must not only compete but al so cooperate. A new sustainable manufacturing paradigm should integrate precision technology, information, communication technology and intellectual creativity, which, however, will not be realized without a coordinated radical initiative. IMS/GNOSIS (Knowledge systematization) aims to establish an integrating platform for this new manufacturing paradigm through the utilization of knowledge intensive strategies focusing on generic representation and communication issues and covering whole life cycle of products and processes, which will be environment conscious, society conscious and human oriented.

\subsection{Framework for researchers of tools and languages}

The engineering of the integrated enterprise is a highly sophisticated, multidisciplinary management, design and implementation exercise during which various forms of descriptions and models of the target enterprise need to be created. To express these models, IFAC/IFIP Task Force believes, more than one modelling language may be needed, which are called Generic Enterprise Modelling Tools and Languages (GEMT\&L).

An Integrating Infrastructure (IIS) is a set of basic information technology services provided by CIMOSA and used to achieve multi-vendor systems integration and communication. It is built on top of operating systems and computer communications facilities. Its purpose is to transform a highly distributed heterogeneous environment into an environment which looks centralized (information can be transparently accessed whenever it is stored) and homogeneous (standard languages are used for data communications, data presentation, data access, machine access, etc.).

\subsection{Framework for strategic coordinators}

In addition to a technical correctness and a practical comprehensiveness, enterprise integration methodologies must be understandable and usable by the communities targeted. IFAC/IFIP Task Force has debated vigorously on how much they can do for publicizing Enterprise Inte gration for the industry. Up to now, as the Task Force in general has been able to offer neither professional service nor consultancy to the industry, there was little hope that they could produce material which could convince managers and decision makers of companies to embark on Enterprise Integration. Therefore, the first priority for the Task Force in the next step will be to build the worldwide EI (Enterprise Integration) Community, which will be composed of practitioners, researchers and consultants, or problem identifiers, problem solvers and strategic coordinators.

A new conceptual and essential scheme to aid this endeavor is an intellectual infrastructure 
named MEGANET, which means "network to support formation of conceptual strategy or policy" and is a network or a global web of extremely creative catalysts and can be used to help managers and professionals solving obstacles in business renovation process and will be discussed fully in the next chapter. (Shibata 1984)

\title{
6 CONCLUSION: TOWARD AN INTELLECTUAL INFRASTR UCTURE FOR THE EXTENDED ENTERPRISE
}

\begin{abstract}
"Before the CEO could hope to change the corporate culture, he had to refine his message and implant it in people's minds. Crotonville, which provided advanced training to $10000 \mathrm{GE}$ executives per year, was the logical place to start....A devotee of creative ferment, he saw Crotonville as a laboratory to create a new kind of management, and a place to produce new ideas. He wanted 'action learning' based on solving real, pending business problems. He wanted participants to learn teamwork skills, while developing companywide networks of contacts to aid them throughout their GE careers." (Tichy and Sherman 1994, pp.155-157)
\end{abstract}

The obstacles to the business renovation are deep rooted and structural, in order to overcome which enterprises are trying to renovate themselves. In the next 10 to 20 years, the modern manufacturing system will have undergone a greater transformation than in any previous period of their existence. This makes a new intellectual infrastructure not only desirable but also indispensable.

However, for sometime to come, the infrastructure can not be a guidance system but should be a social learning process because the barriers between professionals cannot be removed by system alone which is based on our uniform understanding of the axiomatic design theory. The main requirement is that the persons concerned with interprofessional collaboration become so well acquainted with each other's viewpoint that the mutual misunderstanding of specialists is replaced by overlapping views. Therefore, an essential task for the intellectual infrastructure in this endeavor is the creation of learning environment and process which allow specialists and managers as well as customers to self-organize a shared framework of system appreciation and facilitate the renewal of design theory.

Thus, MEGANET is like a catalyst because it guides the change process with no external power or authority. MEGANET is also similar to a gene. MEGANET itself is autonomously decentralized and has all fundamental functional units necessary for the target systems. In this meaning, MEGANET is a model which has a good communication capability with the client. However, the autonomous decentralized system is not a physical, chemical nor biological phenomenon, but is a social phenomenon composed of many people and can creatively evolve forever. What guarantees this evolution is an extraordinary capability of the system to communicate with surrounding environment. Another capability which is indispensable to maintain the unity and harmony of the system is an attractive common vision which should be, again, self-organizd.

From the preceding discussions, it is clear that MEGANET, the concepts of which were 


\begin{tabular}{|c|l|l|}
\hline Steps & \multicolumn{1}{|c|}{$\begin{array}{c}\text { Modelling Methodology } \\
\text { "SINPL" (Shibata) }\end{array}$} & \multicolumn{1}{|c|}{$\begin{array}{c}\text { Framework to apply tools and languages } \\
\text { "MEGANET" }\end{array}$} \\
\hline 1 & Future scenario (S) & Intellect on future and viewpoints \\
\hline 2 & Insight of contradictions (I) & Structural Meta-Model (Figure 3) \\
\hline 3 & Normative objectives (N) & Intellect on policy formation \\
\hline 4 & Strategic plan (P) & Enterprise model (holonic system) \\
\hline 5 & Launching tactics (L) & Intellect on resources and technologies \\
\hline
\end{tabular}

Figure 5 Framework to apply tools and languages: "MEGANET"

originally proposed by Friedmann (1973) and Charles Williams (1973) and modified by Shibata (1984), must play a variety of roles with respect to the obstacles facing transformation as shown in Figure 3. However, because the obstacles are highly interdependent, the framework of MEGANET cannot be such that there is only one function for each obstacle. Rather, the framework that should emerge is a mix of functions to deal with multiple obstacles and interrelationships at the various levels of management as shown in Figure 5.

\section{REFERENCES}

Ahmed, M.S. et al. (1994) Global Concurrent Engineering, Preprints of 2nd

IFAC/IFIP/IFORS Workshop on Intelligent Manufacturing Systems - IMS'94, Vienna, June 13-15

Bernus, P. and Nemes, L. (1994) A Framework to Define a Generic Enterprise Reference Architecture and Methodology, Proceedings ICARCV'94, Singapore, Nov. 8-11

British Aerospace PLC (1994) GLOBEMAN 21 - A World of Resources, British Aerospace PLC, Warton, near Preston

Checkland, P.B. (1981) Systems Thinking, Systems Practice, John Wiley \& Sons

Friedmann, J. (1973) Retracking America, Anchor Press/Doubleday

Garlan, D. (1994) The Role of Software Architecture in Requirement Engineering,

Proceedings of the First International Conference on Requirements Engineering, IEEE Computer Society

Heilbroner, R. (1993) Twenty-first Century Capitalism, UCL Press, London

Hemmens, G.C. (1980) New Directions in Planning Theory, Journal of the American Planning Association 46, 3 (July)

IMS Promotion Center (1994) Final Report of the International Steering Committee adopted at ISC6, Hawaii, 24 to 26 January, IMS Promotion Center, Tokyo

IMS Promotion Center (1995) Introduction to the Full Scale IMS Program (in Japanese and English), Intelligent Manufacturing Systems, vol.6 No.4, IMS Promotion Center, Tokyo Japanese and U.S. Teams (1991) A Shared Vision of Manufacturing Re search, a Joint Report of the Japanese and U.S. Teams participating in the 1990 Japan-U.S. Manufacturing Research Exchange. Review Draft dated March 21, National Academy Press

Katzy, B.R. et al. (1993) CIMOSA Pilot Implementation for Technology Transfer. In 
Yoshikawa, H. and Goossenaerts, J. (eds.) Information Infrastructure Systems for Manufacturing, Northholland

Koestler, A. (1989) The Ghost in the Machine, Arkana, London,

Kuehnle, H. and Schmelzer, S. F. (1995) A New Paradigm - the Practical View of the Factory, IMS Forum '95, IMS Promotion Center, Tokyo

Kurosu, N. (1992) Production Control in Toyota Motor Corp. (in Japanese), Communications of the Operations Research Society of Japan, vol.37 no. 10

Ozbekhan, H. (1974) Thoughts on the Emerging Methodology of Planning. In Ackoff, R.L. (ed.) Systems and Management Annual, Petrocelli Books, New York, Reich, R.B. (1992) The Work of Nations, Vintage, New York

Shibata, Y. (1984) Toward a Policy Guidance System for Complex Innovation, In Eto, H. and Matsui, K. (eds.) $R \& D$ Management Systems in Japane se Industry, Elsevier, Amsterdam Shibata, Y. (1992) Toward a Concept of Meta-game, In Crookall, E. and Arai, K. (eds.) Global Interdependence - Simulation and Gaming Perspectives, Springer, Berlin

Shibata, Y. and Sumita, T. (1993) A Framework of Intellectual Infrastructure for Complex Product Realization, In Goossenaerts, J. and Yoshikawa, H. (Eds.) Design of Information Infrastructure Systems for Manufacturing, North-Holland

Tichy, N.M. and Sherman, S. (1994) Control Your Destiny or Someone Else Will, Harper, New York

Vernadat, F.B. (1994) Business Process and Enterprise Activity modeling: CIMOSA Contribution to GERAM, Proceedings ICARCV'94, Singapore, Nov. 8-11

Williams, C. et al. (1973) Planning and Evaluations Assistance to the NSF Experimental $R$ \& D Incentives Program, Contract URU-72-66, SRI Project 2291, SRI International

Williams, T.J. et al. (1993) Architectures for Integrating Manufacturing Activities and Enterprises, In Yoshikawa, H. and Goossenaerts, J. (eds.) Information Infrastructure Systems for Manufacturing, Northholland

Williams, T.J. (1994) Development of Generic Enterprise Reference Architectures and

Enterprise Integration Methodologies - A Report of the Meeting of the Task Force on Architectures for Enterprise Integration, Internal Memorandum of the IFAC/IFIP Task Force, Vienna Austria, June

Yoshikawa, H. (1992) Proposal for "Artifactual Engineering" - Aims to Make Science and Technology Self-conclusive (in Japanese), ILLUME, vol.4 no.1, Tokyo Electric Power Co.

\section{BIOGRAPHY}

Yusaku Shibata has been hooked on complex problem solving for more than forty years, mainly as an engineering/management staff of Hitachi, Ltd.. Now, he is trying to apply his life long experience to global problems such as future generation manufacturing systems planning in the developed countries and regional social development planning in the developing countries. He is members of the IFAC/IFIP Task Force on Architectures for Enterprise Integration, the Operations Research Society of Japan, the Japanese Society of Organizational Science and the World Future Society. 